\title{
OFICINA LÍTICA DE POLIMENTO NO NOROESTE DO ESTADO DO RIO DE JANEIRO
}

Lithic Polishing Workshop in Northwest of Rio de Janeiro

Nanci Vieira de Oliveira ${ }^{1}$

\section{RESUMO}

No noroeste do Rio de Janeiro, foi identificado um sítio arqueológico do tipo amolador polidor fixo, localizado na Fazenda Santa Inês, município de Miracema. A identificação deste tipo de sítio arqueológico mostra que no Rio de Janeiro, a sua ocorrência não está restrita às praias e ilhas. Assim, este artigo tem como objetivo apresentar e discutir as características deste sítio arqueológico.

Palavras-chave: arqueologia, sítio pré-colonial, polidores

\section{ABSTRACT}

In the northwest of Rio de Janeiro, was identified archaeological site type grinder polisher fixed, located at Fazenda Santa Ines, Miracema municipality. The identification of this type of archaeological site shows that in Rio de Janeiro its occurrence is not restricted to the beaches and islands. Thus, this paper aims to present and discuss the characteristics of this archaeological site.

Keywords: archeology, pre-colonial site, polishers

\section{RESUMEN}

En el noroeste de Río de Janeiro, fue identificado sitio arqueológico tipo pulidor amolador fijo en Fazenda Santa Ines, municipio de Miracema. La identificación de este tipo de yacimiento arqueológico muestra que en Río de Janeiro, su ocurrencia no se limita a las playas e islas. Así, el objetivo de este trabajo es presentar y discutir las características de este sitio arqueológico.

Palabras clave: arqueología, sitio pre-coloniales, pulidoras

\section{Introdução}

A maioria dos sítios arqueológicos registrados no Estado do Rio de Janeiro ocorre no litoral, com predominância de sambaquis construídos por populações pescadoras, coletoras e caçadoras. Com menor frequência existem registros de sítios do tipo Amoladores - Polidores

\footnotetext{
${ }^{1}$ Doutora em História - UNICAMP, Professora Adjunta de Antropologia e Coordenadora do Laboratório de Antropologia Biológica, Universidade do Estado do Rio de Janeiro. E-mail: nancivieira@uol.com.br
} 
Fixos, que correspondem a locais onde são realizadas atividades especificas, ou seja, amolar e polir seus instrumentos líticos.

Embora a maior parte dos registros tenha ocorrido no litoral, em especial em Santa Catarina (TIBURTIUS e BIGARELLA, 1953; ROHR, 1977, 1984; AMARAL, 1995) e Rio de Janeiro (DIAS JUNIOR, 1959; GASPAR e TENÓRIO, 1990; TENÓRIO, 2003; OLIVEIRA e AYROSA, 1991; KNEIP e OLIVEIRA, 2005), estudos posteriores indicam que tais sítios ocorrem em vários locais do Brasil (HERBERTS et al. 2006).

Uma das discussões entre arqueólogos é a relação entre os números de polidores amoladores fixos, de sambaquis e a presença de artefatos polidos nos diferentes sítios arqueológicos. Como não há relações entre as marcas de polimento e amolação de artefatos e identidades étnicas, bem como, os locais de tais práticas específicas geralmente não apresentam os artefatos produzidos, não se pode afirmar que apenas uma única população tenha utilizado tal espaço.

A localização deste tipo de sítio ocorre em uma paisagem que reúne as condições necessárias para a produção de artefatos polidos. Assim, a escolha do suporte advém de suas características físicas particulares, ou seja, tamanho, forma e dureza da rocha, areia com determinada qualidade granulométrica e proximidade da água. Através da abrasão da peça a ser trabalhada contra a superfície da rocha é realizado o polimento, com a utilização de areia úmida e, se formam aos poucos depressões planas ou ligeiramente côncavas.

Há consenso de que a forma das marcas está relacionada aos objetos fabricados, bem como ao gestual do fabricante. A maioria dos arqueólogos concorda que as marcas resultam da prática da confecção de lâminas de machado. Amaral (1995: 81) sugere a possibilidade dos amoladores e polidores fixos terem sido utilizados também para a confecção de outros artefatos polidos, entre os quais tembetás de quartzo e zoólitos.

As formas são descritas como canaletas ou frisos, acanaladas em forma de canoa, circulares e ovais profundas (bacias), circulares e ovais rasas (pratos) e circulares rasas com protuberância no centro (bacia côncavo-convexa). Os frisos podem ser classificados em dois tipos, com depressão em V e com depressão em U. Belem (2012) sugere que os frisos em V seriam utilizados para polir e apontar furadores e agulhas. Os do tipo em U para trabalhar outros tipos de artefatos como bastonetes, arpões e contas de pedra.

Em um esforço de compreender a produção destas formas de depressão na confecção de artefatos polidos, alguns arqueólogos têm realizado estudos da formação do registro arqueológico e análises da cadeia operatória, ou seja, o encadeamento de acontecimentos 
culturais e naturais. Tais estudos têm fornecido algumas informações sobre gestos e desgaste da superfície do suporte de rocha.

Prous et al. (2002) realizaram as experimentações em um bloco de arenito de forma a estabelecer relações entre hora trabalhada e desgaste, bem como gesto e forma do desgaste. Os autores identificaram diferenças entre alisamento e polimento, em que o primeiro resulta em uma abrasão grosseira das superfícies, com auxílio de areia e, o segundo, pode ser obtido com auxílio de um abrasivo muito fino e resulta em uma superfície brilhante. As experimentações apontam à obtenção de alisamento das faces com gestos circulares e, "após cerca de 30 horas de uso total, tinha-se desenvolvido uma bacia oval de 34 x $24 \mathrm{~cm}$, bem rasa - com 0,9 cm de profundidade" (p. 199), para a obtenção de um polimento fino foi utilizado apenas água.

A experimentação de elaboração de machados realizada por Tenório (2003) teve por objetivo obter uma estimativa do desgaste provocado na rocha suporte na fabricação de uma lâmina de machado semelhante às encontradas na Ilha Grande (RJ), o gestual do artesão para determinadas formas (experimentação na areia) e relação entre números de peças produzidas e profundidade do sulco decorrente da abrasão (suporte em granito). A forma acanalada em canoa resultaria de movimentos semicirculares com eixo inclinado para polimentos das faces, formando-se um friso na área central, e o gume na peça trabalhada. A elaboração de 11 lâminas resultou em desgaste de apenas $0,155 \mathrm{~cm}$. A partir dos resultados foi estimado que uma depressão com 2,5 cm seria resultado da elaboração de 177 lâminas de machado.

\section{Localização e descrição}

O presente estudo surgiu de uma visita à fazenda durante a XIII Jornada Científica do Projeto Jovem Talentos para a Ciência do Estado do Rio de Janeiro, realizada no município de Miracema (RJ), quando foi identificado o local como polidor amolador fixo. A Fazenda Santa Inês está localizada no distrito de Paraíso do Tobias, no município de Miracema, no Km 2 da RJ- 186.

A região corresponde a Sub-Bacia Hidrográfica do Rio Pomba, estando o amolador polidor fixo localizado em superfície rochosa de um córrego denominado Ouro Preto, que deságua no Ribeirão do Bonito, tributário do rio Pomba (Figura 1). Em termos geomorfológicos, a região corresponde a unidade de Depressão Interplanáltica do Vale do Rio

Pomba, dominada por colinas, morrotes e morros baixos, com Latossolos e Argissolos Vermelho-Amarelos (DANTAS et al., 2005). 


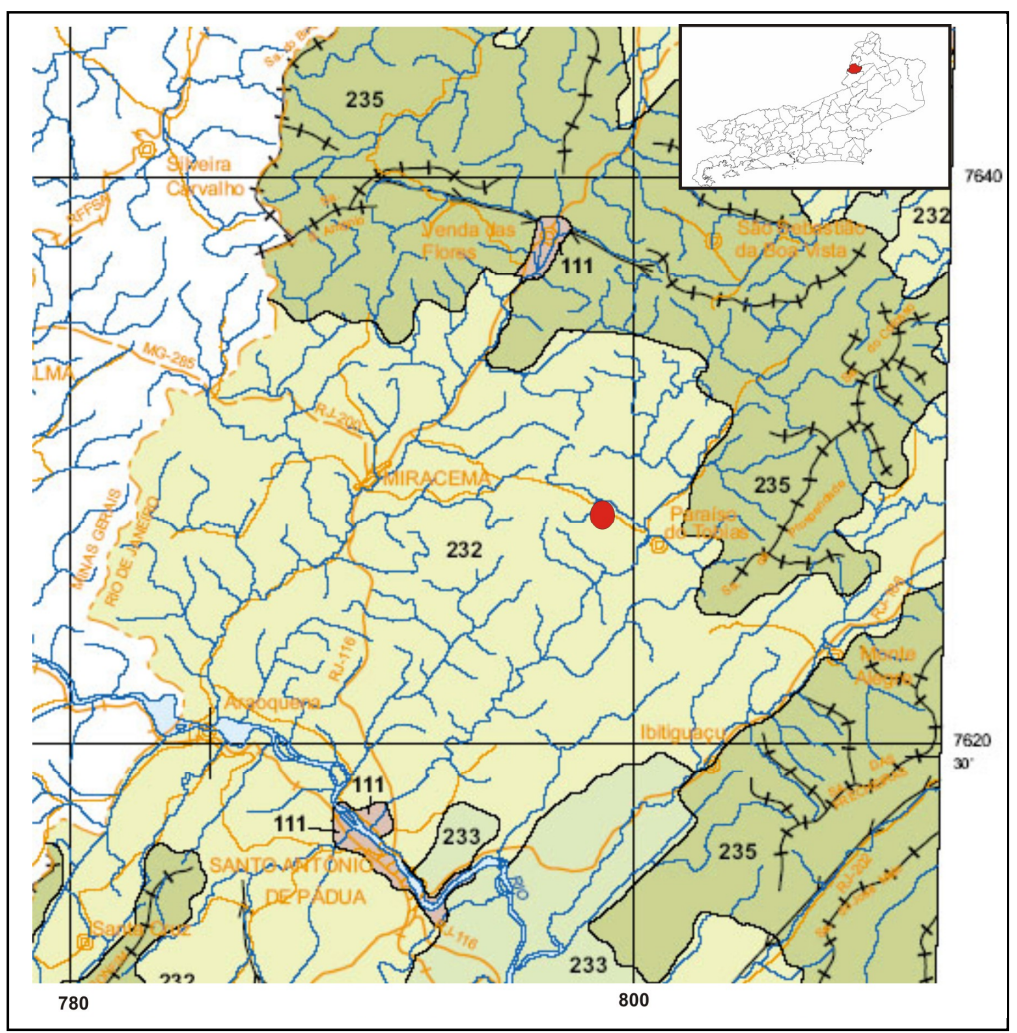

Fig.1: Localização do sítio arqueológico

De acordo com os dados do Departamento de Recursos Minerais do Rio de Janeiro (DRM-RJ), predominam na região de Miracema rochas ortognaisse com composição semelhante ao granito (gnaisses quartzo-feldspáticos), ocorrendo nas proximidades rochas paragnaisses e, nos vales onde há rede de drenagem, os sedimentos quaternários representados por areias, cascalhos e lamas.

O amolador polidor fixo tem como suporte uma superfície de gnaisse em uma pequena queda d'água no córrego Ouro Preto. Este córrego nasce em um dos morros baixos do local e se espraia pelo vale que apresenta sedimento arenoso (Figura 2).

\section{Formas dos sulcos}

Após a identificação durante uma visita como parte de um evento, foi marcado um retorno ao local para o georreferenciamento do sítio (UTM 801.897/ 7628.986) e registro dos seguintes atributos: forma, dimensões (comprimento, largura e profundidade), presença de frisos ou canaletas. Nesta etapa de campo, também foi realizado levantamento sistemático de superfície em toda a propriedade e, principalmente, no vale do córrego Ouro Preto, tendo por 
objetivo identificar outros polidores amoladores fixos e possíveis evidências materiais indicativas de local de habitação.

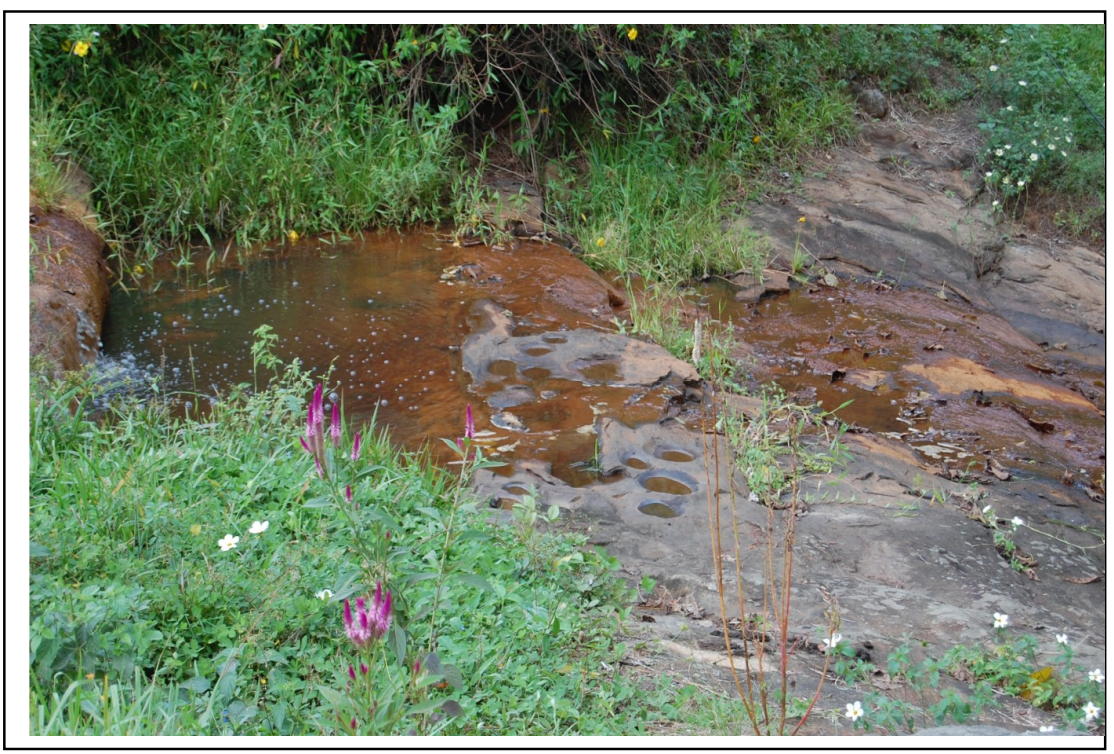

Fig.2: Vista do polidor amolador fixo

Foram identificadas 23 marcas, sendo 19 (dezenove) circulares/ovais e 4 (quatro) frisos, apresentando a maioria destas uma abrasão grosseira das superfícies (Figura 3). A superfície rochosa apresenta irregularidades que foram aproveitadas para a retenção de areia e, algumas parecem que foram ampliadas pela execução do alisamento das faces da peça trabalhada (Figura 4). De forma distinta de outros polidores amoladores fixos, algumas destas marcas não chegaram a desbastar totalmente a superfície e se apresentam irregulares (marca inicial).

No polidor amolador fixo foram observadas as seguintes formas: circular muito rasa (2), circular/oval rasa sem friso (7), circular/oval com friso (3), circular/oval com profundidade (7) e frisos ou canaletas (4).

Em uma das marcas considerada como oval, observamos uma sobreposição de marcas alongadas rasas decorrentes de gestos longitudinais, que poderia estar relacionado ao alisamento de faces ou flancos de um artefato de pequena proporção ( Figura 5 ).

A profundidade das marcas apresenta variação de 0,25 a $4 \mathrm{~cm}$, sendo predominante entre 1 e $3 \mathrm{~cm}$. Ficaram definidas como marcas iniciais as que não alcançaram $1 \mathrm{~cm}$ de profundidade e as rasas as que não ultrapassaram os $2 \mathrm{~cm}$ (Figura 6). 


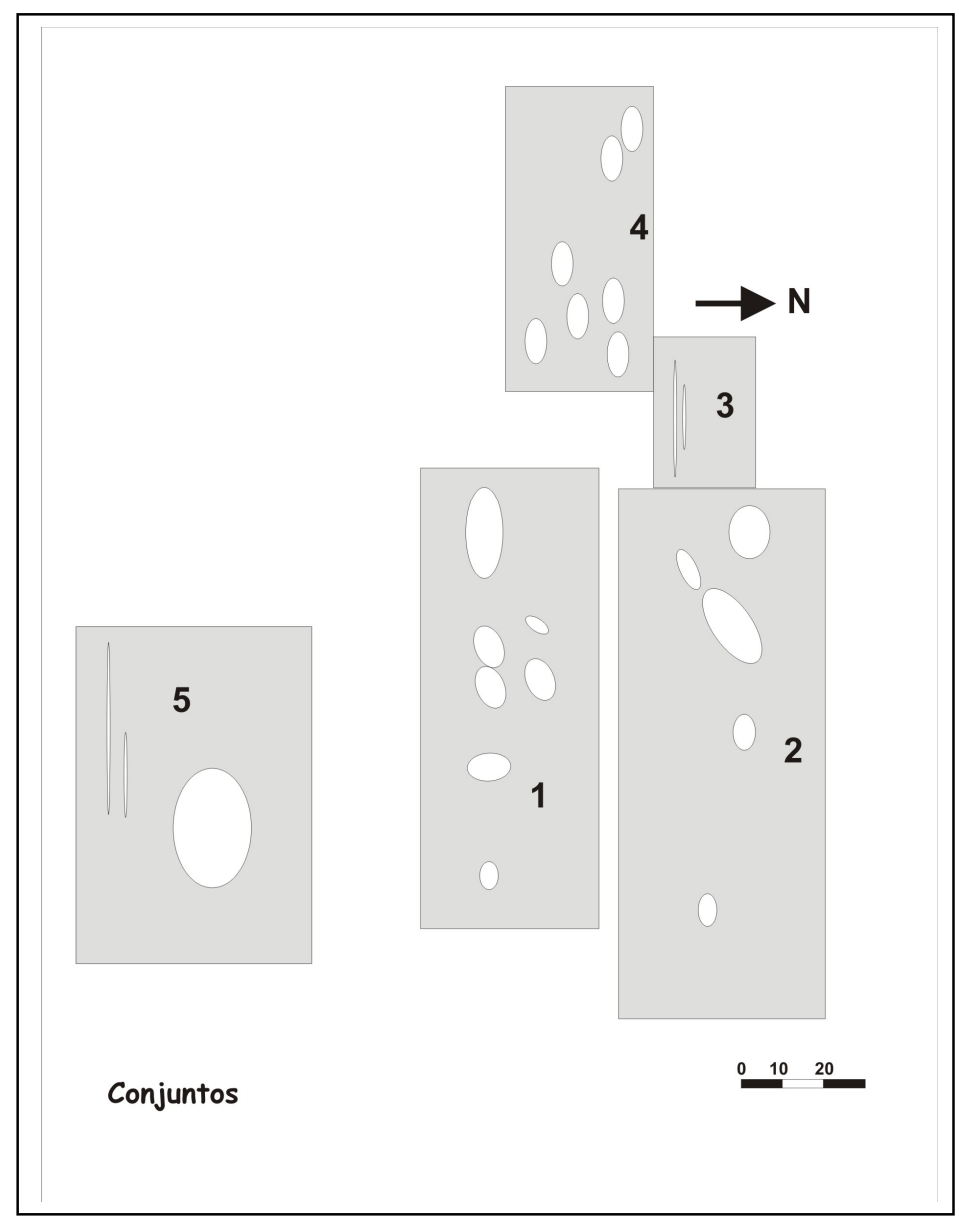

Fig.3: Conjuntos de marcas

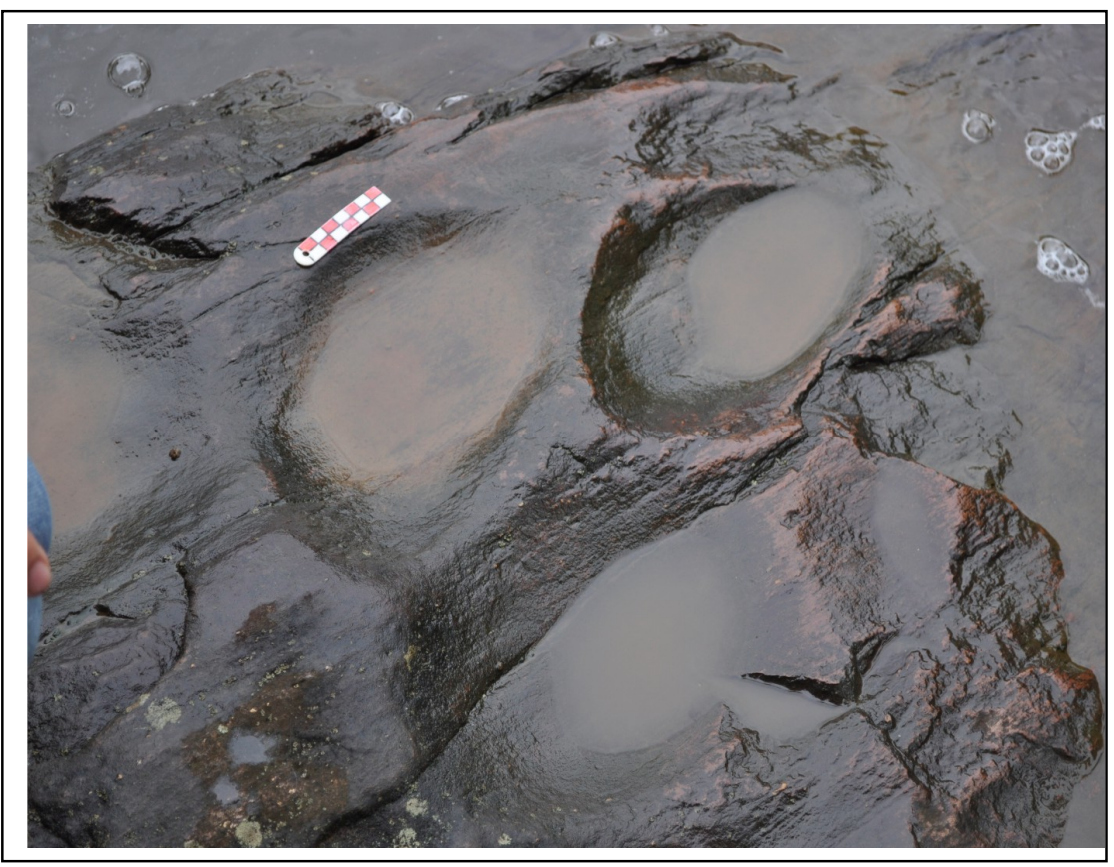

Fig.4: Marcas de polimento 


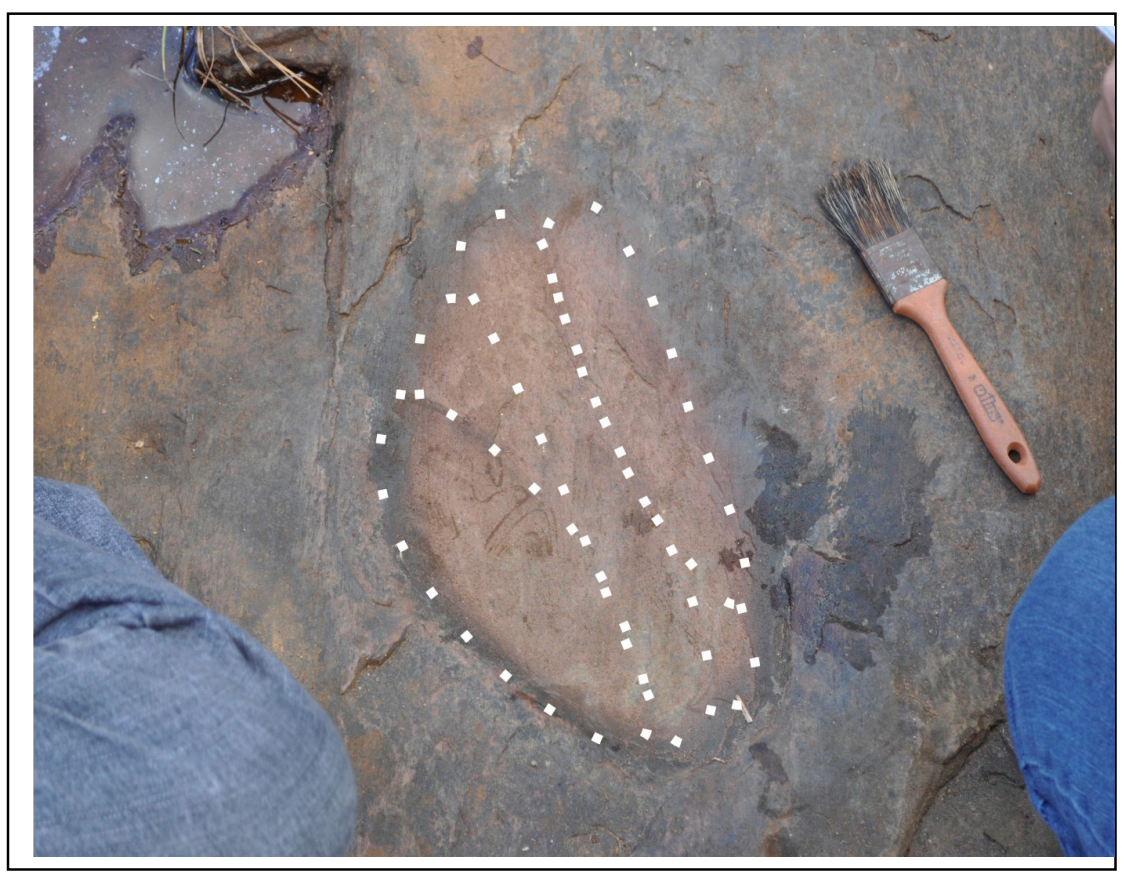

Fig.5: Sobreposição de marcas

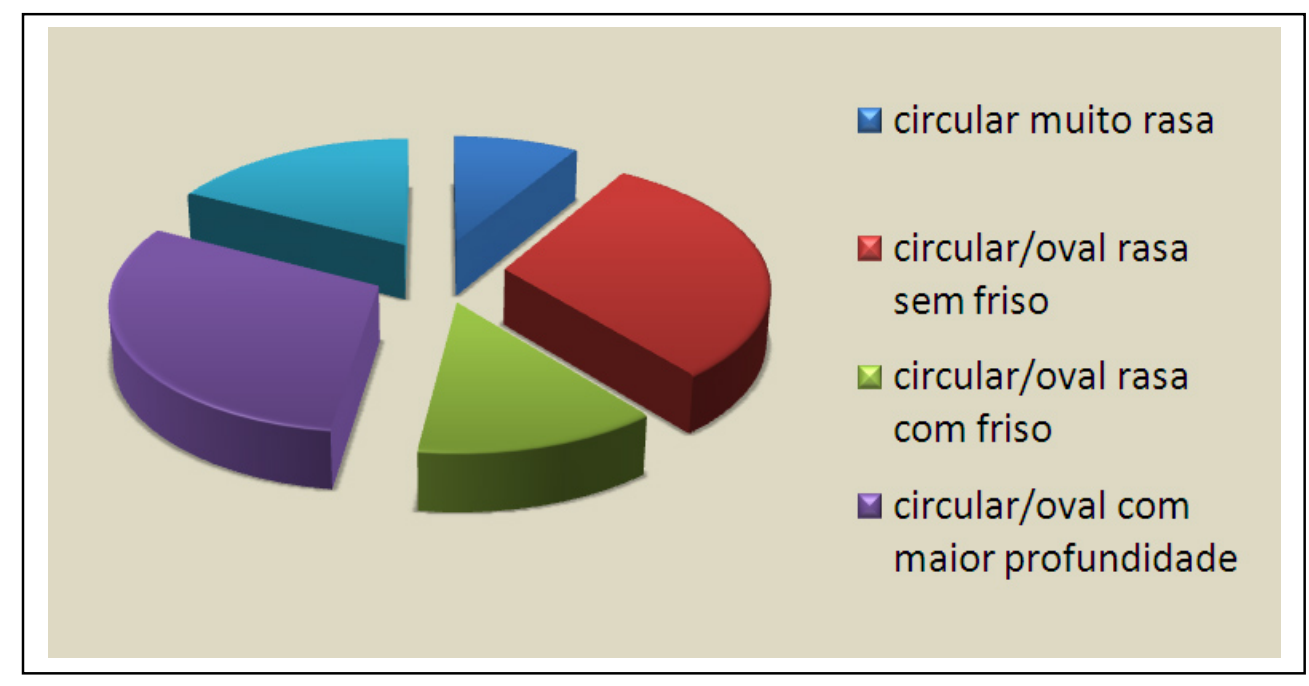

Fig.6: Gráfico

De forma a estabelecer relações entre profundidade das marcas e artefatos produzidos, optamos por utilizar como referência o desgaste obtido na experimentação de Tenório (2003), já que a rocha utilizada apresentava a mesma dureza do suporte de Miracema. De acordo com a autora, a elaboração de onze lâminas de machado decorreu em um desgaste de 0,155 cm em uma base de granito. De acordo com as profundidades das marcas no polidor amolador fixo em Miracema, teríamos desde marcas decorrentes da elaboração de um único artefato polido até as resultantes da elaboração de 25 artefatos. A partir da média das profundidades das 
depressões circulares/ovais, teríamos, aproximadamente, 240 artefatos produzidos neste sítio arqueológico.

\section{Considerações finais}

O polidor amolador fixo da fazenda Santa Inês demonstra que no Rio de Janeiro a ocorrência deste tipo de sítio não está restrita às praia e ilhas. Depressões em forma de canoa, comum em sítios litorâneos, foram ausentes neste sítio do Noroeste fluminense. As dimensões das depressões indicam elaboração de artefatos de menores proporções aos produzidos nos demais sítios estudados no Rio de Janeiro e Santa Catarina.

A identificação deste sítio arqueológico estimulou o interesse da comunidade local, o que resultou na implantação de um projeto de Educação Patrimonial envolvendo jovens do Ensino Médio, tendo por objetivo a realização de um levantamento do patrimônio histórico e arqueológico. Cabe ressaltar que esta região corresponde as áreas proibidas no período colonial até a segunda metade do século XVIII, também denominada como Sertão dos Puris. Assim, a continuidade das pesquisas na região deverá fornecer subsídios para a compreensão das ocupações humanas pré-coloniais no interior do Rio de Janeiro.

O objetivo da Educação Patrimonial é estimular a reflexão junto aos jovens sobre a valorização do patrimônio no contexto urbano e rural, decorrente de uma política de valorização relacionada às representações da elite socioeconômica, em contraposição às culturas relegadas ao esquecimento. Através de palestras e oficinas, os jovens são inseridos na pesquisa e discussões sobre preservação, patrimônio, história indígena na região, vestígios arqueológicos, memória e conhecimentos tradicionais. Ao mesmo tempo, são eles os intermediários entre os pesquisadores e representantes da sociedade local, contribuindo nas avaliações da preservação do patrimônio histórico da região, nas entrevistas e levantamentos de locais com características indicativas de potencial arqueológico.

\section{Referências bibliográficas}

AMARAL, M.M.V. As oficinas líticas de polimento da Ilha de Santa Catarina. Dissertação de Mestrado em História, Porto Alegre, PUC, 1995.

BELEM, F.R. Do Seixo ao Zoólito. A Indústria Lítica dos Sambaquis do Sul Catarinense: Aspectos formais, tecnológicos e funcionais. Dissertação de Mestrado em Arqueologia, MAE/USP, 2012. 
CALDERON, V. "Contribuição para o conhecimento da arqueologia do Recôncavo e do sul do Estado da Bahia" In: Prog. Nac. de Pesq. Arqueol., Publicações Avulsas 26, Belém, Museu Paraense Emílio Goeldi, 1974.

DANTAS, M. E.; SHINZATO, E.; MEDINA, A.I. M.; SILVA, C. R.; PIMENTEL, J.; LUMBRERAS, J.F.; CALDERANO, S. B.; CARVALHO FILHO, A. Diagnóstico Geoambiental do Estado do Rio de Janeiro. Rio de Janeiro, CPRM, 2005.

DIAS JUNIOR, O. F. "Os polidores líticos de Cabo Frio" In: Boletim de História da Faculdade Nacional de Filosofia, Ano I(4), Ano II(5), p. 155-158,1959.

GASPAR, M.D. \& TENÓRIO,M.C. "Amoladores e polidores fixos do litoral brasileiro" In: Revista do CEPA, vol. 17 (20), p.181-190,1990.

OLIVEIRA,N.V. \& AYROSA,P.PS. "Polidores e Amoladores fixos de Piraquara, Angra dos Reis" Programa e Resumos da VI Reun. Cient. SAB, Anais da VI Reun. Cient. SAB, p. 753-760,1991.

PROUS, A. Arqueologia Brasileira, Brasília, Ed. UnB, 1992.

PROUS, A.; ALONSO, M.; PILÓ, H.; XAVIER, L. A. F.; LIMA, A.P.; SOUZA, G.N. "Os Machados Pré-Históricos no Brasil. Descrição de Coleções Brasileiras e Trabalhos Experimentais: Fabricação de Lâminas, Cabos, Encabamento e Utilização" In: Canindé, Xingó, no 2, p. 162-237, 2002.

ROHR, J.A. O sítio arqueológico do Pântano do Sul, SC-F-10. Florianópolis, Governo do Estado de Santa Catarina, 1977.

"O sítio arqueológico da Praia de Laranjeiras, Balneário de Camboriú. Santa Catarina" In: Anais do Museu de Antropologia, 17, UFSC, 1984.

TENÓRIO, M.C. "Os Fabricantes de Machados da Ilha Grande" In: Pré-História da Terra Brasilis, Rio de Janeiro, Ed. UFRJ, p. 233-246, 1999.

TENÓRIO, M.C. O Lugar dos Aventureiros: identidade, dinâmica de ocupação e sistema de trocas no litoral do Rio de Janeiro há 3500 anos antes do presente. Tese de doutorado em História, Faculdade de Filosofias e Ciências Humanas, Pontifícia Universidade Católica do Rio Grande do Sul, Porto Alegre, 2003.

TENÓRIO, M.C., “Os amoladores polidores fixos” In: Revista de Arqueologia, 16, p.87-108, 2003.

TIBURTIUS, G. \& BIGARELLA, I. "Nota sobre os anzóis de osso da jazida paleoetnográfica de Itacoara, Santa Catarina" In: Revista do Museu Paulista (Nova Série), 7, 1953, p.381-387.

UCHÔA, D.P. Arcaico do litoral. In: SCHMITZ, P.; BARBOSA, A.S. \& RIBEIRO, M. (Eds.). "Temas de Arqueologia Brasileira 3. Goiânia: Instituto Goiano de Pré-História e Antropologia" In: Anuário de Divulgação Científica, p.15-32,1978/79/80. 